\title{
Toward a decision support tool for operative dispatching of agricultural bulk goods - A 4PL approach
}

Jens Mehmann ${ }^{1}$,Frank Teuteberg ${ }^{2}$

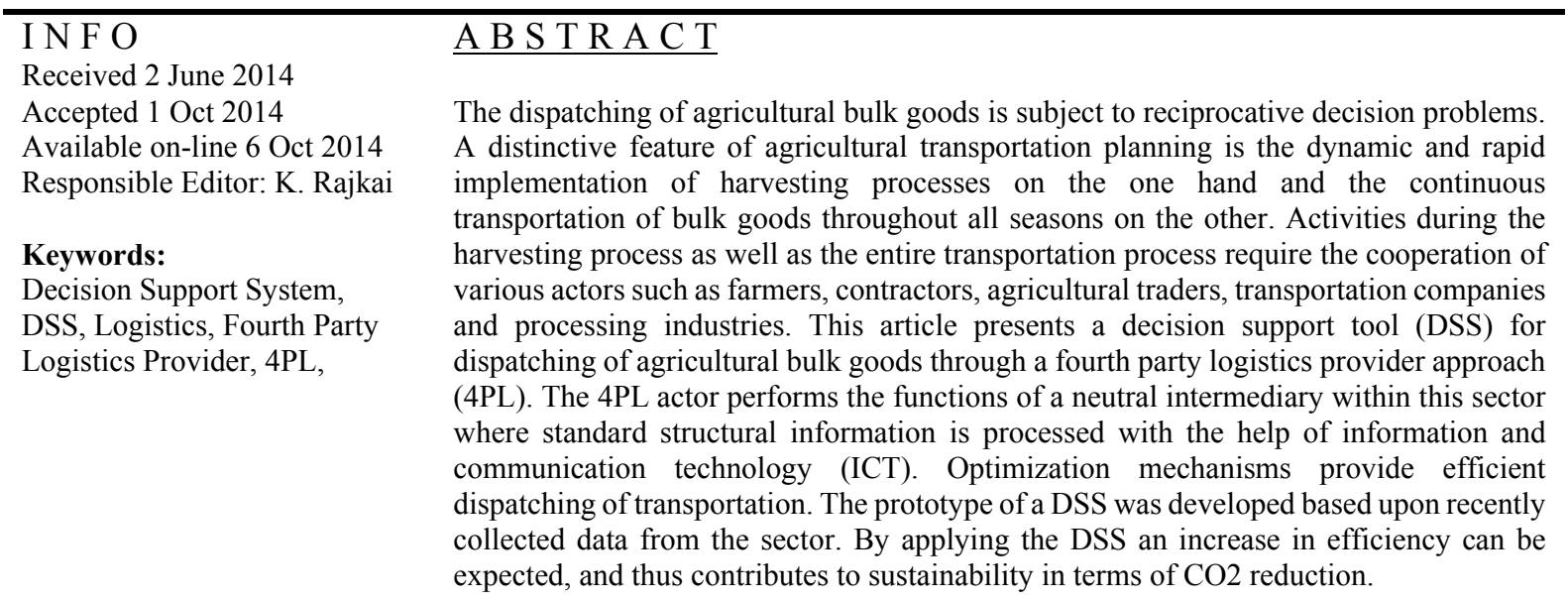

\section{Introduction}

The decline of small receiving docks as well as local processing industries is a result of structural changes in the agricultural sector. As a result, the emergence of large processing industries has led to an increase in transportation activities. In addition, shipment volumes have grown due to increasing trade activities of share holders and the rising biomass energy sector (Searcy et al., 2014; Campbell et al., 2009; Börjesson 1996; Bundesamt für Ernährung, Landwirtschaft und Verbraucherschutz, 2013). As a consequence, an increasing demand for transport wich can only be met with limited transportation capacity.

The annual volume transported by the agricultural sector in Germany is approximately 3,595,373,000 tonnes, of which $76 \%(2,734,098,000$ tonnes $)$ are shipped by commercial road transport (Bundesministerium für Ernährung, Landwirtschaft und Verbraucherschutz, 2011), 90\% of which is inland transportation (Bundesministerium für Ernährung, Landwirtschaft und Verbraucherschutz, 2011). As an example the agricultural sector in the USA transports 512,000,000 tonnes of grain per year: $60 \%$ of this by road traffic, $28 \%$ by rail and $12 \%$ by water (Association of American Railroads 2013). In comparison with Germany, Brazil transports similar volumes: $60 \%$ by road, $22 \%$ by rail and $15 \%$ by water (Vicente Caixeta-Filho, 2003). The distribution of harvests is the central driving factor for the dispatching and transport of agricultural bulk goods in terms of transporting disproportional volumes of goods within a short and dynamic time frame. Further impact factors include the following: people, management, methods, machines, measurements and the environment. As an example, the factor 'environment' is to a large extent characterised by the weather which mainly determines the start and

\footnotetext{
${ }^{1}$ Jens Mehmann

University of Applied Sciences Osnabrueck, Faculty of Economics and Social Sciences, Albrechtstr. 30, 49074 Osnabrück, 
length of the harvest period. Moreover, stock market activities including trade and price developments influence transportation demand. The Global Manufacturing Practice (GMP) requires adequately certified vehicles depending on the type and utilisation of goods (GMP+International B.V., 2013). In addition, the quality of the harvested crop influences its utilisation and thus the type of processing of the good (material) either for foodstuff or feed. Furthermore, the dispatching of transportation depends on the availability of cargo space and machinery. This is important since many harvested crops require specific means of transportation. Currently, the intuition and experience of the individuals involved in dispatching are the main factors influencing dispatching. In general, management is characterised by little connectivity among the actors involved with limited cooperation, whereby each of the actors has his or her own optimisation approach. This applies also to the methods of implementing the dispatch accomplished via telephone, fax and email. Once demand for transportation is generated the aforementioned factors determine dispatch and transaction. As a consequence the synergistic potential possible with a centralised dispatch is lost when applying an ad hoc dispatch approach. A centralised approach, however, enables managers to reduce unloaded mileage and thus use resources more sustainably and protect the environment. The application of information technology including appropriate hard and software solutions are of immense importance for the application of a centralised dispatch approach. The 4PL is a well-proven approach within other sectors (Schmitt, 2006; Prümper and Butz, 2004). This approach has the potential to be adapted to the agricultural sector. For this reason a conceptual framework for the application of the 4PL approach in the agricultural sector was developed. The prototype of this model implies a Decision Support System (DSS) for the operative dispatch of agricultural bulk goods for transportation planning, and at the same time includes the requirements of the involved actors. The application of a number of case studies within the region of Northern Germany demonstrate the synergies and further potential of this centralised dispatch approach.

Section 2 outlines the terminology of the 4PL approach and the applied DSS including specific characteristics of the agricultural sector. Section 3 describes the 4PL approach for transportation transactions as well as the transportation planning module. The validation of the prototype was accomplished with the help of an experiment. Section 4 discusses the results of the experiment, and furthermore, the implications for science and practice. Finally, section 5 provides the conclusions and an outlook for further research activities.

\section{Terms and definitions}

\subsection{The 4PL approach}

The 4PL approach may be seen as a neutral actor within a network that plans, coordinates and controls the requirements of customers while analysing the capacity of the suppliers (Win, 2008; Mukhopadhyay and Setaputra, 2006). Specific information pooling, optimisation and processing support synergies among clients and providers. Clients, in this case, represent actors with transportation demands whereas providers hold transportation capacity. The goal of employing a 4PL approach in the agricultural sector is planning and control based upon the application of information technology. The successful implementation of 4PL in retailing (Prümper and Butz, 2004) as well as automobile production (Schmitt, 2006) are reflected in practice-oriented approaches. These approaches serve as role models in order for this research to be implemented in the agricultural sector.

As in the aforementioned sectors, customers within the agricultural sector should be able to acquire goods safely and transparently. Moreover, transportation service suppliers may expect efficient resource utilisation. In order to implement these requirements a DSS approach for the decision support for all involved actors was selected. For this reason a thorough analysis of the previous ad hoc workflow for a transportation transaction including the methods, mechanisms and processes applied is required.

\subsection{Decision Support System}

Currently, the dispatch of transportation is chiefly based upon personal preferences and experience of the dispatcher. This includes transportation pooling as well as the selection of carriers (Caputo et al., 2005). In summary, this may result in suboptimal decisions (Ching-Chung and Soflarsky, 2003). However, DSS as transportation planning tools have the potential to support dispatchers in selecting the 
appropriate carriers, bundling orders and optimizing routing. As a consequence the number of possible variables can be reduced. For instance, Schönberger and Kopfer (2010) describe a DSS-driven approach for capacity increase in transportation logistics especially for road freight transport. Furthermore, Hu and Sheng (2014) demonstrate solutions for the reduction of unloaded mileage and related high transportation costs. These problems may be solved with a model-based DSS, increased information flow, better management and optimization approaches. Ching-Chung and Soflarsky (2003) introduced an automated carrier selection for the transportation of engines based upon a DSS.

Examples from the literature such as the aforementioned describe partial solutions for transportation planning. However, a DSS in combination with a 4PL approach for logistics in the agricultural sector was not identified. This article describes the development of a DSS prototype for dispatching agricultural bulk goods, including specific characteristics of the bulk goods as well as the logistical requirements of a $4 \mathrm{PL}$, which is, as yet, a novel approach.

\subsection{Characteristics of the sector}

An online survey conducted between October and November 2012 among 145 carriers in the sector resulted in the following conclusion: transportation orders, planning and management are implemented based upon individual preferences and perceived capabilities of the actors. At the moment transportation orders, planning and management are ad hoc processes so the potential for improvement among the actors involved is conceivable (Mehmann et al., 2013). The online survey was divided into three categories: the first section contained general questions about the company's profile; the second section examined issues in the 4PL approach with a subdivision into technical, cooperative and economic requirements as well as issues of corporate development. Furthermore, interviewees were encouraged to provide comments, remarks and suggestions in the third section. All together the questionnaire contained 33 questions, either open questions or Likert scale. With a response rate of $21 \%$ and the results of additional expert interviews, actors could confidently be characterized as highly self-reliant in their functionality and their activities. Based upon their resources each of the actors is capable of selling goods (trader, shipper), purchasing (recipients, manufacturers), transporting (carriers), storing and/or processing goods (recipient). In this way transportation demand is generated. Depending on their resources each actor may have different functions (trader, recipient, carrier, shipper). Each actor has the required information about transportation and decides independently if the information will be shared or if the transport will done with their own equipment. Depending on the influence of harvesting and trading activities, transport may be implemented under less than efficient conditions than if the actor joins other actors in the sector to combine their transport activities.

Based upon these insights a conceptual framework for the transportation transaction within agricultural bulk good logistics was developed. Much emphasis was placed on information transparency within the sector. In addition, the added value of a 4PL approach was verified with the result that the main feature of transportation planning is an improved utilization of resources.

\section{A DSS for agricultural bulk good logistics}

\subsection{A conceptual framework for the DSS}

The 4PL system for transportation transactions of agricultural bulk goods is clustered into four subsystems based on the findings of the survey: (1) transport order demand, (2) transport order planning, (3) transport order transaction, and (4) transport order controlling. These subsystems are subject to further development as a single DSS in future research.

(1) Transport order demand is entered in a standardized graphical user interface (GUI) where the transport order must be indicted including a selection of baseline data such as transportation volume, means of transport, loading and unloading address and time slot. In this way a standardized data-set as well as a communication tool are generated. This subsystem enables users to obtain an overview of both the previously registered orders as well as the planned transport order demand.

(2) Transport order planning dispatches transportation orders and generates supply routes taking into account the input parameters. The selection of carriers is based upon the available data set. After 
calculating the supply routes these are offered to the carrier, who may accept or decline the offer. In case of acceptance a preliminary order is filed. If the offer is declined, it will be issued for dispatch once again.

(3) The transport order transaction provides the means to control and monitor transportation activities of the carriers and informs consignors (sender) as well as recipients of the arrival and unloading of goods. Furthermore, it communicates the completion of the transportation order so that the invoicing can be processed.

(4) Transport order controlling monitors the progress of transportation orders with the help of performance indicators. A comparison of budgeted and actual figures generates reports for the actors involved. A report for the carrier may be generated in the form of a performance display including the transportation status as well as the information flow. The dispatcher receives feedback on whether or not automatically generated routes are feasible. For the consignors and recipients of goods the compliance with the timeframe is indicated. The performance indicators are a controlling tools for network principles of the 4PL approach such as the collaborative transaction of transportation. Figure 1 illustrates the overall conceptual framework including its network actors: trader, consignor (sender), recipient, transport provider and service provider.

- The trader trades goods and requests that the transport transaction be implemented under efficient conditions in terms of costs and emissions.

- The consignor (sender) wants the traded goods to be shipped within the agreed time frame. Therefore, he/she must provide loading facilities.

- The recipient aims to receive purchased goods within the agreed-on time frame. Therefore, he/she has to provide unloading facilities.

- The transport provider wants to transport goods with the most efficient use of own resources.

- The service provider aims to align the requirements of all involved transportation actors efficiently. Furthermore, information flow is bundled and in this way synergies for the increase in efficiency are invoked. Hence, transparent information flow among all involved actors as well as with the service provider is required.

Based upon the requirements of the agricultural sector including the involved actors a prototype DSS was designed and evaluated as the main function of the 4PL approach. 


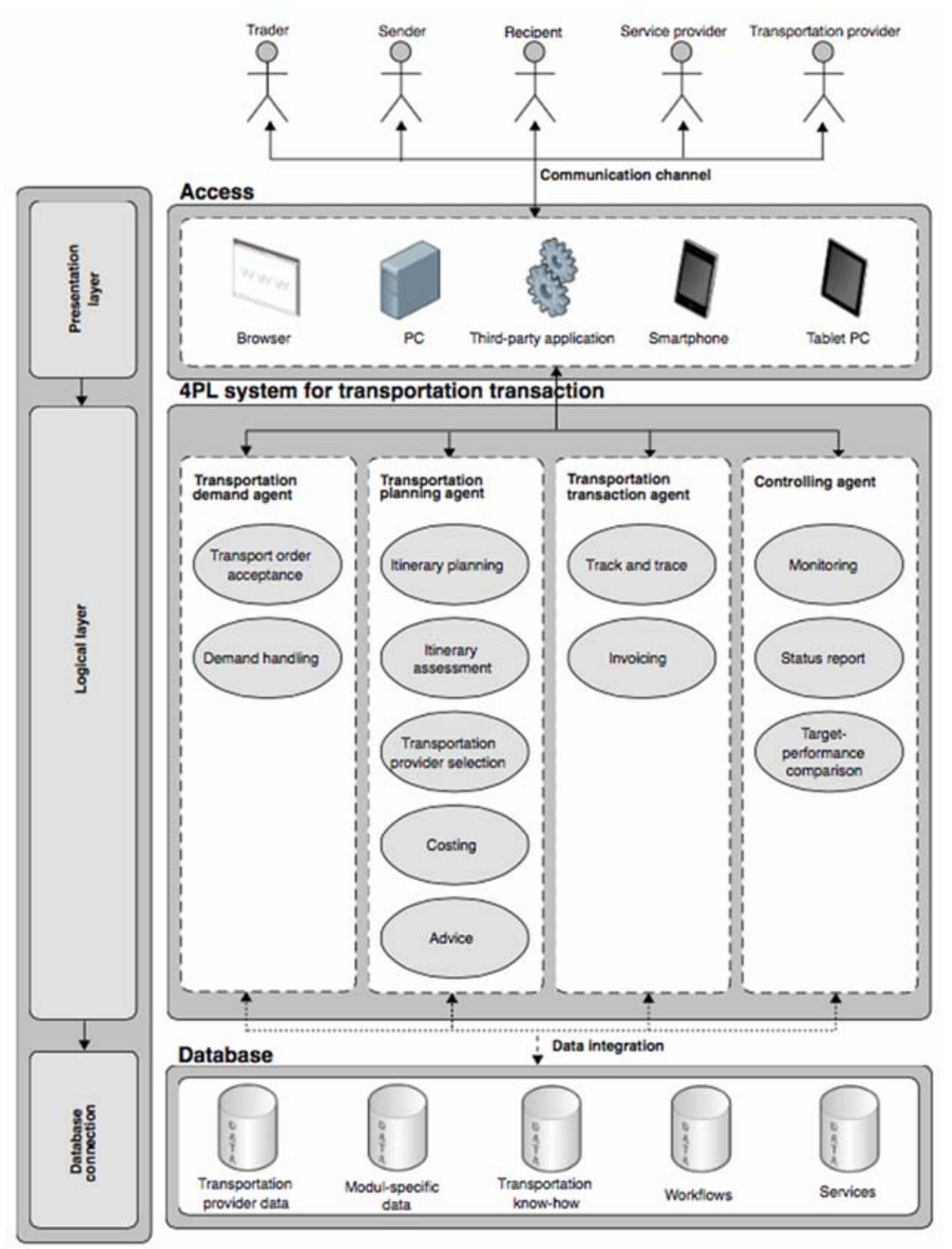

Figure 1. The overall conceptual framework of the 4PL approach

\subsection{The transportation planning agent}

Previously dispatch was an ad hoc process, where each single transportation order is individually called in and dispatched. Transport orders of the involved actors are the initial basis for the planning process of the DSS. The analysis of transportation order demand enters a database. Thereby, transportation orders are collected according to designated timeslots. The transportation planning DSS generates delivery routes based upon available transportation orders and parameters such as maximum working hours, average cruising speed and the selected carrier. A single delivery route may encompass several transportation orders. The target criterion for this is the minimization of unloaded mileage. In this way resources such as vehicles, fuel and working hours can be saved. Another effect of decreased mileage is a possible reduction of greenhouse gas emissions and other air pollutants. Based upon the results of the transportation planning module the dispatcher receives proposals for itinerary planning which may be conveyed to a transportation provider. Data transmission can be implemented either automatically or manually via fax.

Given a time slot of one to eight weeks the dispatch effort may be seen as a travelling salesman problem (TSP) (Laporte, 1992). For shorter time slots, however, dispatching is a special case of the vehicle routing problem (VRP), as called pickup and delivery problem (PDP) (Nowak et al., 2009). In light of the demanding search algorithms of these methods and the large data set, several heuristics have been tested together with a complete lookup procedure. These heuristics are: the tabu search approach 
(TS) and the simulated annealing (SA). For the TS further derivatives have been applied for an optimization of the calculation.

Based upon typical data for the agricultural sector an experiment was conducted to examine the prototype DSS for transportation planning.

\subsection{Experimental setup and analysis}

The input data of the experiment consisted of about 150,000 transport orders transacted between 2010 and 2012, and included approximately 200 transportation providers of agricultural bulk goods logistics. One of the whole saletraders in the agricultural sector became a research partner in the project and provided all relevant data based upon previous transportation activities. This data set contains: loading and unloading addresses, clients, materials, volumes, prices, transportation order numbers and transportation demand figures. In addition, the related geo data of loaders and consignors have been generated. Because of the real-world character of the data from past activities realistic parameters were delineated for the experiment. Because of the availability of loading and unloading positions, the corresponding time slot for the transaction vehicle activities each transportation order was available in the form of a potential transport order demand analysis within a mySQL database. Further data such as volumes, prices, loading and unloading times were neglected in the first round. A computer with the following features was used for all calculations: processor: Intel® Core ${ }^{\mathrm{TM}}$, i5-3550CPU@3,30GHz, memory: 8.00 GB; Windows 7 Enterprise-Service Pack 1, System: 64 Bit OS. The computer represents a common machine in the sector.

The transportation planning that provided decision support was designed according to practiceoriented scenarios in the form of the sum of potential transportation orders. The classification for the transport orders to be dispatched in the experiment was: 20, 50, 100, 1000 and 2000 orders. About a hundred transportation orders correspond with a dispatch effort of about half a day, whereas 2000 orders correspond to an effort of about two weeks.

The following termination conditions for the heuristics were selected including the typical dynamic influence factors within the sector: $1 \mathrm{~h}$ (short-term redispatch), $2 \mathrm{~h}$ (dispatch morning or afternoon) and $8 \mathrm{~h}$ (dispatch during night). Furthermore, the carriers that should return home after $40 \mathrm{~h}$ and traveling at a cruising speed of $60 \mathrm{~km} / \mathrm{h}$ provide the framework conditions for the dispatch effort. The ultimate goal of the experiment was the optimal reduction of unloaded mileage with itinerary planning, which was not possible with ad hoc dispatch. The experiment started with the calculations of the simulated annealing, the tabu search 1 and the modified tabu search 2. Table 1 lists the relevant results of the experiment. The table shows the calculated transport orders by the chosen algorithm over a runtime. Furthermore the savings in comparison with the ad hoc dispatching are documented. The complete lookup procedure is implemented and can be employed for future optimization. However, the dispatch of more than 11 transportation orders with this algorithm is too complex.

Figure 2 displays the GUI for a dispatcher. This GUI facilitates an overview of baseline parameters (e.g., time slot, transport orders, type of procedure), and provides monitoring of the generated delivery tour. Moreover, a graphical output of the route can be issued for carriers.

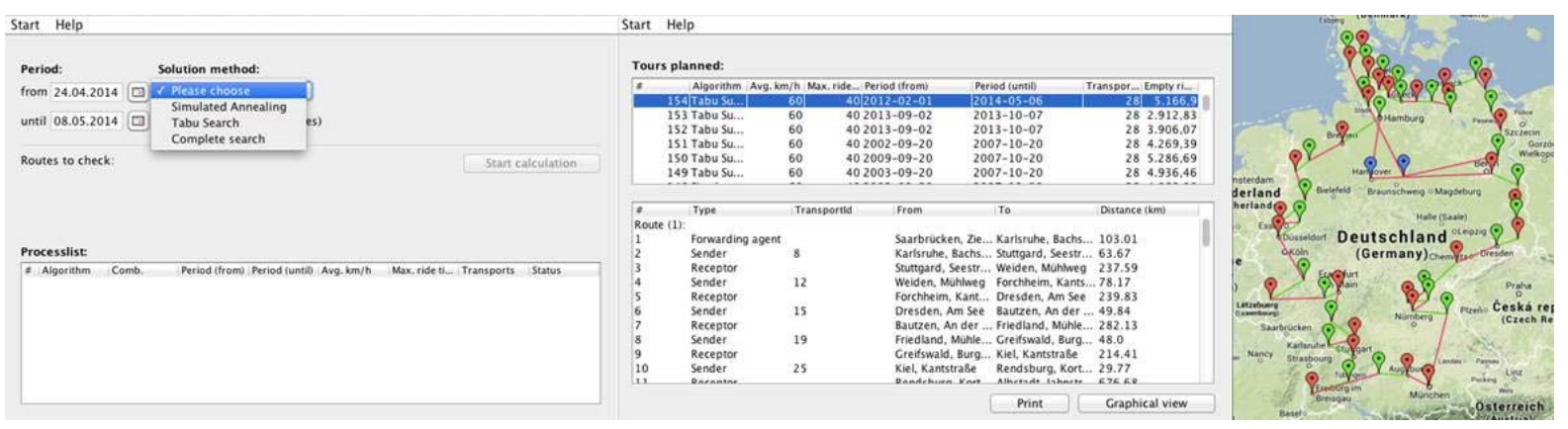

Figure 2. GUI for a dispatcher

ISSN 2061-862X (http://www.magisz.org/journal) 
Table 1. Results of the experiment

\begin{tabular}{|c|c|c|c|c|c|c|c|c|c|c|c|}
\hline \multirow[t]{2}{*}{ TO } & \multirow[t]{2}{*}{ algorithm } & \multicolumn{3}{|c|}{ unloaded mileage $(\mathrm{km})$} & \multirow{2}{*}{$\begin{array}{l}\text { unloaded } \\
\text { mileage } \\
\text { (ad hoc) }\end{array}$} & \multicolumn{3}{|c|}{ savings $(\mathbf{k m})$} & \multicolumn{3}{|c|}{$\begin{array}{c}\text { Cost savings } \\
(\%)\end{array}$} \\
\hline & & 1h & $2 \mathrm{~h}$ & $8 h$ & & 1h & $2 \mathrm{~h}$ & $8 \mathrm{~h}$ & 1h & $2 \mathrm{~h}$ & $8 \mathrm{~h}$ \\
\hline \multirow{3}{*}{20} & TS & 3316 & 3316 & 3316 & \multirow{3}{*}{5404} & 2088 & 2088 & 2088 & $39 \%$ & $39 \%$ & $39 \%$ \\
\hline & SA & 3288 & 3287 & 3287 & & 2117 & 2117 & 2117 & $39 \%$ & $39 \%$ & $39 \%$ \\
\hline & TS2 & 3288 & 3288 & 3288 & & 2117 & 2117 & 2117 & $39 \%$ & $39 \%$ & $39 \%$ \\
\hline \multirow{3}{*}{50} & TS & 11774 & 11453 & 11229 & \multirow{3}{*}{15197} & 3423 & 3744 & 3968 & $23 \%$ & $25 \%$ & $26 \%$ \\
\hline & SA & 11585 & 11186 & 11055 & & 3612 & 4012 & 4142 & $24 \%$ & $26 \%$ & $27 \%$ \\
\hline & TS2 & 11080 & 11037 & 11015 & & 4118 & 4160 & 4182 & $27 \%$ & $27 \%$ & $28 \%$ \\
\hline \multirow{3}{*}{100} & TS & 19151 & 19151 & 18741 & \multirow{3}{*}{29591} & 10440 & 10440 & 10850 & $35 \%$ & $35 \%$ & $37 \%$ \\
\hline & SA & 18965 & 18902 & 18387 & & 10625 & 10689 & 11204 & $36 \%$ & $36 \%$ & $38 \%$ \\
\hline & TS2 & 18591 & 18591 & 18490 & & 11000 & 11000 & 11101 & $37 \%$ & $37 \%$ & $38 \%$ \\
\hline \multirow{3}{*}{200} & TS & 34841 & 34829 & 33889 & \multirow{3}{*}{52944} & 18103 & 18116 & 19055 & $34 \%$ & $34 \%$ & $36 \%$ \\
\hline & SA & 33968 & 30279 & 28504 & & 18976 & 22665 & 24440 & $36 \%$ & $43 \%$ & $46 \%$ \\
\hline & TS2 & 30129 & 30105 & 29008 & & 22815 & 22839 & 23936 & $43 \%$ & $43 \%$ & $45 \%$ \\
\hline \multirow{3}{*}{1000} & TS & 153406 & 150057 & 150051 & \multirow{3}{*}{224429} & 71022 & 74371 & 74377 & $32 \%$ & $33 \%$ & $33 \%$ \\
\hline & SA & 147775 & 142080 & 141237 & & 76653 & 82349 & 83192 & $34 \%$ & $37 \%$ & $37 \%$ \\
\hline & TS2 & 147768 & 147646 & 147242 & & 76660 & 76782 & 77187 & $34 \%$ & $34 \%$ & $34 \%$ \\
\hline \multirow{3}{*}{2000} & TS & 311329 & 295081 & 285974 & \multirow{3}{*}{440493} & 129164 & 145412 & 154519 & $29 \%$ & $33 \%$ & $35 \%$ \\
\hline & SA & 289829 & 287303 & 273751 & & 150664 & 153190 & 166742 & $34 \%$ & $35 \%$ & $38 \%$ \\
\hline & TS2 & 283770 & 282679 & 281001 & & 156723 & 157814 & 159492 & $36 \%$ & $36 \%$ & $36 \%$ \\
\hline & & & & & & & \multicolumn{2}{|c|}{ Average TS } & $32 \%$ & $33 \%$ & $34 \%$ \\
\hline & & & & & & & \multirow{2}{*}{\multicolumn{2}{|c|}{$\frac{\text { Average SA }}{\text { Average TS2 }}$}} & $34 \%$ & $36 \%$ & $38 \%$ \\
\hline & & & & & & & & & $36 \%$ & $36 \%$ & $37 \%$ \\
\hline
\end{tabular}

\section{Results}

Based upon the framework conditions described, a savings of unloaded mileage of about $32-38 \%$ is possible. This was achieved with any of the provided heuristics. If the calculation time is increased, any calculation procedure gains an additional reduction of merely 1-4\%. The mileage saving depends upon the number of transport orders. In general, the TS2 procedure is most suitable for small timeframes of $1-2 \mathrm{~h}$. In the event of longer timeframes as well as overnight dispatches simulated annealing is the most favourable procedure. The DSS supports transportation provider selection, since this is automated within the itinerary planning. The bundling of information flow of transportation orders enables the DSS to reduce unloaded mileage on the one hand, and on the other hand, utilises the carrier's resources optimally since freight capacity is dispatched on a long-term basis.

The introduction of the 4PL approach in conjunction with a DSS for transportation order planning including all required software and hardware has significant implications for the practice. Yet, the automated dispatch of half a day (100 transportation orders) has the potential of saving $11,200 \mathrm{~km}$. This, of course, may entail a significant reduction of personnel deployment and transportation resources such as fuel, toll charges and vehicle depreciation. Based upon these results, a $\mathrm{CO} 2$ reduction of approximately $8,400 \mathrm{~kg}$ may be achieved within a half a day calculation $\left(\mathrm{CO}_{2} 2013\right.$ - calculation $)$.

\section{Summary}

This article provides a conceptual framework of a 4PL system for the transportation transaction of agricultural bulk goods. As a central function of the 4PL transportation planning a DSS was developed. The evaluation of this DSS was implemented with transportation data typical for this sector, which resulted in a practice-oriented trial.

Apart from the conceptualisation the experiment demonstrates the potential for saving costs and other resources within the agricultural sector. This has been achieved with both improved information flow and a bundled transportation planning by the 4PL. These two features characterise the added value of the 4PL approach. The calculated results may be used to convince actors to participate in such a novel dispatch programme within the agricultural sector. 
From the scientific point of view the correlation of a growing number of transportation orders to be dispatched with the increasing quality of planning results including the incorporation of specific sectoral factors is most interesting. Furthermore, the extension of run time for calculation has a positive effect on the results in terms of their resources savings potential. Yet, the 4PL-based dispatching approach allows for both a more concise itinerary planning and a bundling of transportation orders, which was previously not possible because of the high complexity of the transportation system under the aforementioned specific conditions.

However, the experiment has a number of limitations: in the first instance, itinerary planning strongly depends upon the number of transportation orders addressed including their specific characteristics. This may yield results that deviate from expectations when employing different data samples. Furthermore, applied heuristics as well as the hardware and software used impose limitations on the results. Different algorithms and higher performing hardware may also cause deviatiations in results and faster run times.

Further research should develop additional DSS based upon the aforementioned main functions of the 4PL. Moreover, the modification of previously applied heuristics may be examined and further optimizations of the calculations could be found. Finally, an improvement of the information flow and its user-friendliness among actors remains a challenge. This is because of the varying use of communication means within the sector. In addition, hardware and software requirements should be kept on a level that does not exceed the budgeting of the involved actors.

\section{References}

Association of American Railroads 2013. Railroads and Grain.

Bundesamt für Ernährung, Landwirtschaft und Verbraucherschutz. 2013. Preisvolatilität und Spekulation auf den Märkten für Agrarrohstoffe. Available at: http://www.bmelv.de

Bundesministerium für Ernährung, Landwirtschaft und Verbraucherschutz 2011. Transport landwirtschaftlicher Güter, Tabelle 354.

Bundesamt für Naturschutz 2010. Bioenergie und Naturschutz - Synergien fördern, Risiken vermeiden. Available at: http://www.bfn.de

Börjesson, P. I. I. 1996. Emissions of CO2 from biomass production and transportation in agriculture and forestry. Energy Conversion and Management. 37(6-8):1235-1240.

Caixeta-Filho, J.V. 2003. Transportation and Logistics in Brazilian Agirculture, Agriculture Outlook Forum 2003.

Campbell, J. E.,Lobell, D.B.,Field, C.B 2009. Greater Transportation Energy and GHG Offsets from Bioelectricity Than Ethanol. Science 22, 324(5930): 1055-1057.

Caputo, A.C., Fratocchi, L. and Pelagagge, P.M. 2005. A framework for analysing long-range direct shipping logistics. Industrial Management \& Data Systems. 105(7):876-899.

Ching-Chung, K. and Soflarsky, F. 2003. An automated system for motor carrier selection. Industrial Management \& Data Systems. 103 (7): 533-539.

GMP+ International B.V. 2013. GMP+ Feed Certification scheme: GMP+4.1.

$\mathrm{CO}^{2} 2013$ - Calculation. Available at: https://www.prima-klima-weltweit.de

Hall, N.G., Sethi, S.P. and Sriskandarajah, C. 1991. On the complexity of generalized due date scheduling problems. European Journal of Operational Research. 51(1):100-109.

Hu, Z.-H. and Sheng, Z.-H. 2014. A decision support system for public logistics information service management and optimization. Decision Support Systems. 59:219-229.

Laporte, G. 1992. The Traveling Salesman Problem: An overview of exact and approximate algorithms. European Journal of Operational Research. 59(2):231-247.

Mukhopadhyay, S.K. and Setaputra, R. 2006. The role of 4PL as the reverse logistics integrator. International Journal of Physical Distribution \& Logistics Management. 36(9):716-729.

Mehmann, J., Teuteberg, F., Freye, D. 2013. Requirements for a 4PL-Platform in After-Crop Logistics; in Proceeding of the EFITA 2013 (EFITA, WCCA, CIGR VII). Turin 
Nowak, M., Ergun, O. and White, C.C. 2009. An empirical study on the benefit of split loads with the pickup and delivery problem. European Journal of Operational Research. 198(3):734-740.

Prümper, W. and Butz, C. 2004. Der Internal 4PL — Best Practice „Metro Group“. In Baumgarten, H., Darkow, I.-L. and Zadek, H. (Eds.). Supply Chain Steuerung und Services. 261-269. Springer

Rickenberg, T.A., von Mettenheim, H.-J. and Breitner, M.H. 2012. „Green by IT” -Nachhaltiger Gütertransport durch Entscheidungsunterstützungssysteme. Multikonferenz Wirtschaftsinformatik 2012. 1487-1498.

Schmitt, A. 2006. 4PL-Providing ${ }^{\text {TM }}$ als strategische Option für Kontraktlogistikdienstleister: Eine konzeptionellempirische Betrachtung, DUV.

Schönberger, J. and Kopfer, K. 2010. Kapazitätssteuerung in der Transportlogistik - Ein Ansatz zur Ertragsmaximierenden Resspurcen-Allokation im Straßengüterverkehr. Multikonferenz Wirtschaftsinformatik 2010. 383 ff.

Searcy, E., Hess, J., Tumuluru, J., Ovard, L., Muth, D., Trømborg, E., Wild, M., Deutmeyer, M., Nikolaisen, L., Ranta, T. and Hoefnagels, R. 2014. Optimization of Biomass Transport and Logistics. in Junginger, M., Goh, C.S. and Faaij, A. (Eds.), International Bioenergy Trade, Lecture Notes in Energy, Vol. 17, Springer Netherlands. 103123.

Win, A. 2008. The value a 4PL provider can contribute to an organisation. International Journal of Physical Distribution \& Logistics Management. 38 (9). 674-684. 